\title{
Adolescent deliveries in rural Cameroon: an 8-year trend, prevalence and adverse maternofoetal outcomes
}

\author{
Valirie Ndip Agbor ${ }^{1 *}$, Clarence Mvalo Mbanga ${ }^{2}$ and Tsi Njim ${ }^{3,4}$
}

\begin{abstract}
Background: Adolescent deliveries remain a global public health concern especially in low- and middle-income countries where $95 \%$ of these deliveries occur. In Cameroon, adolescent pregnancies have a high disease burden due to their association with adverse pregnancy outcomes. We sought to evaluate the prevalence, trend and adverse maternofoetal outcomes of adolescent deliveries in a rural community in Cameroon.
\end{abstract}

Method: We carried out a retrospective register analysis of 1803 singleton deliveries in two health facilities located in the Oku sub-division over an 8-year period (2009 to 2016). We excluded: records without maternal age, babies born before arrival, birthweights less than $1000 \mathrm{~g}$, multiple deliveries and deliveries before 28 weeks gestation. Data analysis was done using Epi info 7.0.8.3. The Fisher's exact test was used to compare categorical variables, while the chi-square test for trends was used to determine time trends. P-values below $5 \%$ were considered statistically significant.

Results: The 8-year prevalence of adolescent deliveries was $20.4 \%(95 \% \mathrm{Cl}=18.6-22.4)$ with a significant, downward trend between 2009 and 2016 ( $P$ trend $=0.05$ ). Second-fourth degree perineal tears were more likely to complicate adolescent (Age $<20$ years) deliveries compared with their adult (Age $\geq 20$ years) counterparts $(\mathrm{OR}=2$. 9; $95 \% \mathrm{Cl}=1.8-4.7 ; p<0.001)$. Also, babies born to adolescent mothers were more likely to have a low birthweight $(\mathrm{OR}=1.7 ; 95 \% \mathrm{Cl}=1.1-2.6 ; p=0.009)$ and be asphyxiated at the fifth minute of life $(\mathrm{OR}=3.2 ; 95 \% \mathrm{Cl}=1.9-5.5$; $p<0.001)$. Over an eight-year period, the downward trend in the prevalence of adolescent deliveries was associated with a significant decrease in the trend of neonatal asphyxia at the fifth minute. Married adolescents and their babies were as likely to develop the complications of adolescent delivery such as second-fourth degree perineal tears $(\mathrm{OR}=0.8 ; 95 \% \mathrm{Cl}=0.4-1.6 ; p=0.456)$, low birthweight $(\mathrm{OR}=2.1 ; 95 \% \mathrm{Cl}=0.9-4.7 ; p=0.070)$ and fifth minute neonatal asphyxia ( $\mathrm{OR}=0.9 ; 95 \% \mathrm{Cl}=0.4-2.0 ; p=0.832)$ as single adolescents and their babies.

Conclusion: The prevalence of adolescent deliveries in this rural community is high with one of every five babies born to an adolescent mother. Despite the downward trend indicating a decrease in adolescent deliveries, our study demonstrates the need to reinforce and effectively apply existing government-based public health programme to target key indicators of adolescent pregnancy in Cameroon.

Keywords: Adolescent deliveries, Adverse maternal and foetal outcomes, Rural Cameroon

\footnotetext{
* Correspondence: nvagbor@gmail.com

'Ibal Sub-divisional Hospital, Oku, Northwest Region, Cameroon

Full list of author information is available at the end of the article
} 


\section{Plain English summary}

Pregnancy and delivery in adolescence is a major health problem worldwide, especially in low- and middleincome countries where over 95\% of these deliveries occur. Like other low-income countries, the situation in Cameroon is marked by a high prevalence of adolescent pregnancies, and poor health outcomes for both the mother and her unborn baby. Most studies on adolescent deliveries in Cameroon have been conducted either in urban or semi-urban areas. To the best of our knowledge, this is the first study conducted in a rural area of the country to evaluate the prevalence and the adverse maternal and foetal outcomes of adolescent deliveries over an 8 year period.

We reviewed the delivery registers containing information on deliveries conducted within an 8-year period (2009-2016) in two health facilities in a rural subdivision in Cameroon. After excluding records without maternal age, babies born before arrival to the health facilities, birthweights less than $1000 \mathrm{~g}$, multiple deliveries and deliveries before 28 weeks gestation; 1803 singleton delivery records were retained for this study.

Adolescent deliveries represented $20.4 \%$ of the 1803 deliveries included in this study. Also, the prevalence of adolescent deliveries significantly decreased over the 8year study period. Interestingly, a similar decrease in birth asphyxia at the fifth minute of life was also noted. Moreover, compared with adult deliveries, adolescent deliveries were more likely to be complicated by a second-fourth degree perineal tear and these adolescent mothers were more likely to have low birthweight babies, and babies asphyxiated at the fifth minute of life. Finally, married adolescents and their babies were as likely to develop the complications of adolescent delivery such as second-fourth degree perineal tears, low birthweight and birth asphyxia at the fifth minute of life as single adolescents and their babies.

In conclusion, our study depicts a high prevalence of adolescent deliveries in this rural sub-division. In fact, it shows that one in every five babies is born to an adolescent mother. Even though, this community is experiencing a downward trend in the prevalence of adolescent deliveries, there is a dire need not only to reinforce the existing government-based public health policies to target the key indicators of adolescent pregnancy in Cameroon, but also to effectively apply them.

\section{Background}

Varying definitions have been attributed to adolescent pregnancy. Generally, adolescent or teenage pregnancy refers to pregnancy occurring in a girl aged 13 to 19 years. Adolescent pregnancy is a major public health concern worldwide, especially in sub-Saharan Africa. Globally, $11 \%$ of all births result from adolescent pregnancy, with $95 \%$ of these births occurring in lowand middle-income countries [1]. In fact, the complications of adolescent pregnancy and childbirth is the second cause of death among girls aged 15-19 years worldwide [1], and this is 2.5 times higher in girls below 15 years of age [1]. Factors such as: customs and traditions that encourage early marriages, poor knowledge on reproductive sexual health, wrong contraceptive use (as over half of unmarried adolescents do not use effective contraception) have been attributed to adolescent pregnancy [1-4]. Delivery in adolescence is associated with higher risks of hypertensive disorders, caesarean delivery, low birthweight (LBW), neonatal asphyxia, prematurity and stillbirth $[1,3,5-7]$.

The situation of adolescent pregnancy in Cameroon, like other sub-Sahara African countries, needs to be addressed. Adolescent girls constitute 23.2\% (5.4 million) of the total Cameroonian population, $44.5 \%$ of whom reside in rural areas [4]. About $84 \%$ of the married, and half of unmarried, sexually active adolescent girls in Cameroon are not on any contraceptive method [4]. By 2011, 25\% of adolescent girls in Cameroon had already begun their reproductive life; $21 \%$ of whom had at least a child and $4 \%$ were pregnant for their first time. In addition, the proportion of adolescent girls who had already begun their reproductive life was remarkably elevated in the rural (34\%) compared to urban areas (18\%) [4]. Contrasting prevalences of adolescent pregnancy have been reported throughout the national territory ranging from $2.8-26.5 \%[5,6,8-10]$; with a national prevalence of $14.2 \%$ [10]. The burden of adolescent deliveries is likely to be higher in rural communities where education, especially education on reproductive sexual health is poorer. Most of the studies on adolescent pregnancy in Cameroon were mostly focused on urban and sub-urban areas. Also, there is the common misconception that married adolescents are more equipped to deal with the burden of pregnancy than their single counterparts. However, studies have reported no difference in the complications of adolescent deliveries between married and single adolescents [6]. To add to the body of knowledge on this subject, we carried out this study to evaluate the trend in the prevalence and adverse maternofoetal outcomes of adolescent deliveries; and to determine if married adolescents were precluded from having adverse outcomes when compared to single adolescents in two health facilities in rural Cameroon.

\section{Methods}

\section{Study design, duration and setting}

We conducted a retrospective - register analysis of delivery records during a period of 8 years, from January 1st, 2009 to December 31st, 2016, in two health facilities in the Oku Health District (OHD): Oku district hospital 
and Kevu primary health centre. These facilities conduct, in roughly equal proportions, about $40 \%$ of an average of 900 deliveries per month reported in this Health District. The OHD is in the Oku sub-division of the Bui - division, Northwest Region Cameroon. During the study period, the OHD was managed by three medical practitioners. The Oku district hospital was managed by a single doctor, while the Kevu primary health centre was managed by a nurse with no training in midwifery. Consequently, all caesarean sections were done at the district hospital. Referral in the health district is usually from the primary health care centres to the district hospital. This referral pattern is usually ineffective due to difficulties in accessing the main district hospital. The OHD has an estimated population of 93, 000 inhabitants, and majority of whom live below the poverty limit of one dollar per day.

\section{Data collection}

All singleton deliveries recorded within the study period were included. Records: without maternal age ( $82 \%$ of excluded records), babies born before arrival (3.1\% of excluded records), birthweights less than $1000 \mathrm{~g}$ (4.3\% of excluded records), multiple deliveries (4.5\% of excluded records) and deliveries before 28 weeks gestation $(6.2 \%$ of excluded records) were excluded from our study.

We collected data on the sociodemographic characteristics of the study population (age, marital status), clinical characteristics (gravidity, parity, gestational age, human immunodeficiency virus [HIV] status and sex of the neonates), maternal outcome (mode of delivery, postpartum haemorrhage and second-fourth degree perineal tear) and foetal outcome (birthweight, fifth minute Apgar score and term of the pregnancy which was determined from the gestational age). Caesarean deliveries were only recorded as from the year 2014 .

\section{Statistical analysis}

All data were entered and analysed using Epi info 7.0.8.3 software after verifications for errors. Before statistical analysis, variables were categorised as shown in Table 1. Quantitative variables were presented as means with their corresponding standard deviation (SD) while categorical variables were presented as frequencies and percentages. A Fisher's exact test was used to compare categorical variables. The Odd's ratio (OR) with corresponding 95\% confidence interval (CI) were used to estimate the degree of association that could exist between categorical variables. The Chi-square test for trends was used to determine time trends. $P$-values below $5 \%$ were considered statistically significant.
Table 1 Definition of operational variables

\begin{tabular}{|c|c|}
\hline Age & $\begin{array}{l}\text { Adolescent ( }<20 \text { years) versus adult deliveries } \\
(\geq 20 \text { years) }\end{array}$ \\
\hline Adolescents & $\begin{array}{l}\text { Early adolescence (10-16 years) versus late } \\
\text { adolescence (17-19 years) [6]. }\end{array}$ \\
\hline Gravidity & $\begin{array}{l}\text { 1. Primigravida (Women at their first pregnancy) } \\
\text { 2. Multigravida ( } 2-4 \text { pregnancies) } \\
\text { 3. Grand multigravida (>4 pregnancies) }\end{array}$ \\
\hline Parity & $\begin{array}{l}\text { 1. Primiparous (Women at their first delivery) } \\
\text { 2. Multiparous ( } 2-4 \text { deliveries) } \\
\text { 3. Grand multiparous ( }>4 \text { deliveries) }\end{array}$ \\
\hline Gestational age & $\begin{array}{l}\text { 1. Preterm delivery: Delivery from } 28 \text { to } 36 \text { weeks } \\
\text { of gestation } \\
\text { 2. Term delivery: Delivery from } 37 \text { to } 42 \text { weeks } \\
\text { of gestation } \\
\text { 3. Post-term delivery: Delivery above } 42 \text { weeks } \\
\text { of gestation }\end{array}$ \\
\hline $\begin{array}{l}\text { Apgar score at fifth } \\
\text { minute }\end{array}$ & Neonatal asphyxia. Yes $(<7)$ versus No $(\geq 7)$ \\
\hline Low birthweight & Babies born with a weight $\leq 2600 \mathrm{~g}$ [28]. \\
\hline High birthweight & Babies born with a weight $\geq 3850$ [29]. \\
\hline
\end{tabular}

\section{Results}

We included 1803 of the 2343 deliveries recorded within our defined study period, giving a response rate of $77 \%$. The proportion of included delivery records were roughly the same for both facilities (District Hospital $=905$ [50.2\%] versus Health centre $=898[49.8 \%])$. The ages of the 1803 records analysed ranged from 14 to 49 years, with a mean age of $26.0 \pm 6.5$ years. Only two cases of delivery in girls below 15 years of age were noted. Adolescent deliveries constituted 368 of the 1803 deliveries, representing a prevalence of $20.4 \%(95 \% \mathrm{CI}=18.6-$ 22.4). Of the 368 adolescents $40.5 \%$ were married while $22 \%$ were multiparous. Eleven (3.0\%) of the 368 adolescents were positive for HIV (Table 2). The rate of caesarean deliveries was at $0.9 \%$.

Adolescent deliveries were significantly associated with: second - fourth degree perineal tears $(\mathrm{OR}=2.9$; 95\% CI $=1.8-4.7 ; p<0.001), \mathrm{LBW}(\mathrm{OR}=1.7 ; 95 \%$ $\mathrm{CI}=1.1-2.6 ; p=0.009)$ and neonatal asphyxia at the fifth minute of life $(\mathrm{OR}=3.2 ; 95 \% \mathrm{CI}=1.9-5.5$; $p<0.001$ ), compared with adult deliveries (Tables 3 and 4). Seven cases of postpartum haemorrhage were recorded in this study, all of which resulted from adult deliveries. Married adolescents were as likely to have complications from deliveries as single adolescents (Table 5).

We noticed a significant downward trend in the annual prevalence of adolescent deliveries (from a prevalence of $24.2 \%$ [58/240] in the year 2009 to $15.9 \%$ [32/ 201] in 2016; P trend $=0.05$ ) and neonatal asphyxia at fifth minute of life among babies of adolescent mothers (from a prevalence of $8.3 \%$ [5/60] in the year 2009 to 
Table 2 Characteristics of the study population

\begin{tabular}{|c|c|c|c|c|}
\hline \multirow[t]{2}{*}{ Variable } & \multicolumn{2}{|l|}{ Adolescent, N (\%) = 368 (20.4) } & \multirow{2}{*}{$\begin{array}{l}\text { Adult, N } \\
(\%)=1435 \\
(79.6)\end{array}$} & \multirow{2}{*}{$\begin{array}{l}\text { Total N } \\
(\%)=1803 \\
(100)\end{array}$} \\
\hline & Early adolescent, N (\%) = 57 (15.5\%) & Late adolescent, N (\%) = $311(84.5)$ & & \\
\hline \multicolumn{5}{|l|}{ Marital status } \\
\hline Single & $47(82.5)$ & $171(55.0)$ & $220(15.4)$ & $439(24.5)$ \\
\hline Married & $10(17.5)$ & $140(45.0)$ & $1207(84.6)$ & $1356(75.5)$ \\
\hline \multicolumn{5}{|l|}{ Gravidity $(n=1760)$} \\
\hline Primigravida & $52(91.2)$ & $230(75.2)$ & $153(11.0)$ & $434(24.7)$ \\
\hline Multigravida & $5(8.8)$ & $76(24.8)$ & $769(55.0)$ & $850(48.3)$ \\
\hline Grand multigravida & $0(0.0)$ & $0(0.0)$ & $478(34.0)$ & $478(27.0)$ \\
\hline \multicolumn{5}{|l|}{ Parity $(n=1761)$} \\
\hline Primiparous & $53(93.0)$ & $232(75.8)$ & $162(11.6)$ & $447(25.4)$ \\
\hline Multiparous & $4(7.0)$ & $74(24.2)$ & $764(54.6)$ & $842(47.8)$ \\
\hline Grand multiparous & $0(0.0)$ & $0(0.0)$ & $472(33.8)$ & $472(26.8)$ \\
\hline \multicolumn{5}{|c|}{ Gestational age $(n=1647)$} \\
\hline Term & $28(54.9)$ & $181(64.2)$ & $820(62.4)$ & $1029(62.5)$ \\
\hline Preterm & $21(41.2)$ & $81(28.7)$ & $436(33.2)$ & $538(32.7)$ \\
\hline Post term & $2(3.9)$ & $20(7.1)$ & $58(4.4)$ & $80(4.8)$ \\
\hline \multicolumn{5}{|c|}{ Mode of delivery $(n=1802)$} \\
\hline Vaginal & $57(100.0)$ & $308(99.4)$ & $1421(99.0)$ & $1786(99.1)$ \\
\hline Caesarean & $0(0.0)$ & $2(0.6)$ & $14(1.0)$ & $16(0.9)$ \\
\hline \multicolumn{5}{|l|}{ Maternal HIV status } \\
\hline Positive & $1(1.7)$ & $10(3.2)$ & $70(4.9)$ & $81(4.5)$ \\
\hline Negative & $56(98.3)$ & $301(96.8)$ & $1362(95.1)$ & $1719(95.5)$ \\
\hline \multicolumn{5}{|l|}{ Gender of infant } \\
\hline Male & $36(45.6)$ & $157(50.5)$ & $729(61.0)$ & $911(51.1)$ \\
\hline Female & $31(54.4)$ & $154(49.5)$ & $701(49.0)$ & $886(48.9)$ \\
\hline
\end{tabular}

$H I V$ human immunodeficiency virus, $N$ frequency

$3.2 \%[1 / 31]$ in 2016; $\mathrm{P}$ trend $=0.04$ ) over the 8-year period, Fig. 1. However, we observed no significant trend in the prevalence of the following adverse outcomes of adolescent deliveries: LBW ( $\mathrm{P}$ trend $=0.61$ ) and second - fourth perineal tear $(\mathrm{P}$ trend $=0.35)$.

\section{Discussion}

Our study demonstrates that adolescent deliveries represent one-fifth of the total deliveries in the Oku subdivision. Even though this prevalence falls within the range $2.8-26.5 \%[5,6,8-10]$ reported in Cameroon, it is

Table 3 Maternal outcomes of adolescent deliveries

\begin{tabular}{|c|c|c|c|c|}
\hline Outcome & Adolescent (Age < 20 years) & Adult (Age $\geq 20$ years) & OR $(95 \% \mathrm{Cl})$ & $p$ - value \\
\hline \multicolumn{5}{|c|}{ Postpartum haemorrhage } \\
\hline Yes, n (\%) & $0(0.0)$ & $7(0.5)$ & - & - \\
\hline No, n (\%) & $368(100.0)$ & $1796(99.5)$ & & \\
\hline \multicolumn{5}{|c|}{ Caesarean delivery } \\
\hline Yes, n (\%) & $2(0.5)$ & $14(1.0)$ & $0.6(0.1-2.6)$ & 0.337 \\
\hline No, n (\%) & $365(99.5)$ & $1421(99.0)$ & & \\
\hline \multicolumn{5}{|c|}{ Second - fourth degree perineal tear } \\
\hline Yes n (\%) & $32(8.7)$ & $45(3.1)$ & $2.9(1.8-4.7)$ & $<0.001$ \\
\hline No, n (\%) & $336(91.3)$ & $1390(96.7)$ & & \\
\hline
\end{tabular}


Table 4 Foetal outcomes of adolescent deliveries

\begin{tabular}{|c|c|c|c|c|}
\hline Outcome & Adolescent (Age < 20 years) & Adult (Age $\geq 20$ years) & OR $(95 \% \mathrm{Cl})$ & $p$-value \\
\hline \multicolumn{5}{|c|}{ Low birthweight } \\
\hline Yes, n (\%) & $35(9.8)$ & $84(5.9)$ & $1.7(1.1-2.6)$ & 0.009 \\
\hline No, n (\%) & $324(90.2)$ & $1329(94.1)$ & & \\
\hline \multicolumn{5}{|c|}{ High birthweight } \\
\hline Yes, n (\%) & $10(2.8)$ & $94(6.7)$ & $0.4(0.2-0.9)$ & 0.004 \\
\hline No, n (\%) & $349(97.2)$ & $1320(93.3)$ & & \\
\hline \multicolumn{5}{|c|}{ Neonatal asphyxia (5th min Apgar) } \\
\hline Yes, n (\%) & $24(6.7)$ & $31(2.2)$ & $3.2(1.9-5.5)$ & $<0.001$ \\
\hline No, n (\%) & $335(93.3)$ & $1379(97.8)$ & & \\
\hline \multicolumn{5}{|l|}{ Stillbirth } \\
\hline Yes, n (\%) & $7(1.9)$ & $18(1.3)$ & $1.5(0.6-3.7)$ & 0.233 \\
\hline No, n (\%) & $360(98.1)$ & $1417(98.7)$ & & \\
\hline \multicolumn{5}{|c|}{ Preterm deliveries } \\
\hline Yes, n (\%) & $102(30.6)$ & $436(33.2)$ & $0.9(0.7-1.2)$ & 0.396 \\
\hline No, n (\%) & $231(69.4)$ & $878(66.8)$ & & \\
\hline \multicolumn{5}{|c|}{ Post-term deliveries } \\
\hline Yes, n (\%) & $22(6.6)$ & $58(64.4)$ & $1.5(0.9-2.5)$ & 0.067 \\
\hline No, n (\%) & $311(93.4)$ & 1259 (95.6) & & \\
\hline
\end{tabular}

$O R$ odd's ratio, $\mathrm{Cl}$ confidence interval, $n$ frequency

much higher than most reports from studies conducted in urban $[8,10]$ and semi-urban $[5,6,10]$ settings. In addition, this prevalence follows closely the high prevalence of adolescent deliveries of $26.5 \%$ recorded in 2005 in Maroua, Cameroon [10]; a city where early marriages are a part of the cultural values of the people [10]. Indeed, almost half of the adolescents in our study were married. Factors such as: encouragement of early marriages, poverty, lack of proper education on sexual and reproductive health, decrease awareness and wrong use of contraceptive methods, and low educational ambition have been attributed to high rates of adolescent pregnancies, and consequently, adolescent deliveries in lowincome countries [11]. Also, there was no difference in delivery outcomes between married adolescents and single adolescents. This finding emphasises the need to address the sexual and reproductive health needs for unmarried adolescents, who usually get less health care support than their married counterparts. In this rural area, with a high prevalence of early marriages, our study showed that married adolescents were just as likely to have complications from deliveries as their single counterparts. These findings were similar to those of Nim et al. who reported a similar risk of adverse delivery outcomes between adolescents and their adult counterparts [6]. This supports the assertion that adolescents might be generally ill-equipped to deal with the burden of pregnancy.

Table 5 Comparison of maternal and foetal outcomes between single and married adolescents

\begin{tabular}{|c|c|c|c|c|}
\hline Outcome & Single adolescent & Married adolescent & OR $(95 \% \mathrm{Cl})$ & $p$-value \\
\hline \multicolumn{5}{|c|}{ Second - fourth degree perineal tear } \\
\hline Yes, n (\%) & $17(7.8)$ & $15(10.1)$ & $0.8(0.4-1.6)$ & 0.456 \\
\hline No, n (\%) & $202(92.2)$ & $134(89.9)$ & & \\
\hline \multicolumn{5}{|c|}{ Low birthweight } \\
\hline Yes, n (\%) & $26(12.2)$ & $9(6.2)$ & $2.1(0.9-4.7)$ & 0.070 \\
\hline No, n (\%) & $187(87.8)$ & $137(93.8)$ & & \\
\hline \multicolumn{5}{|c|}{ Neonatal asphyxia at 5th minute of life } \\
\hline Yes, n (\%) & $15(7.0)$ & $9(6.2)$ & $0.9(0.4-2.0)$ & 0.832 \\
\hline No, n (\%) & $198(93.0)$ & $137(93.8)$ & & \\
\hline
\end{tabular}

OR odd's ratio, $\mathrm{Cl}$ confidence interval, $n$ frequency 


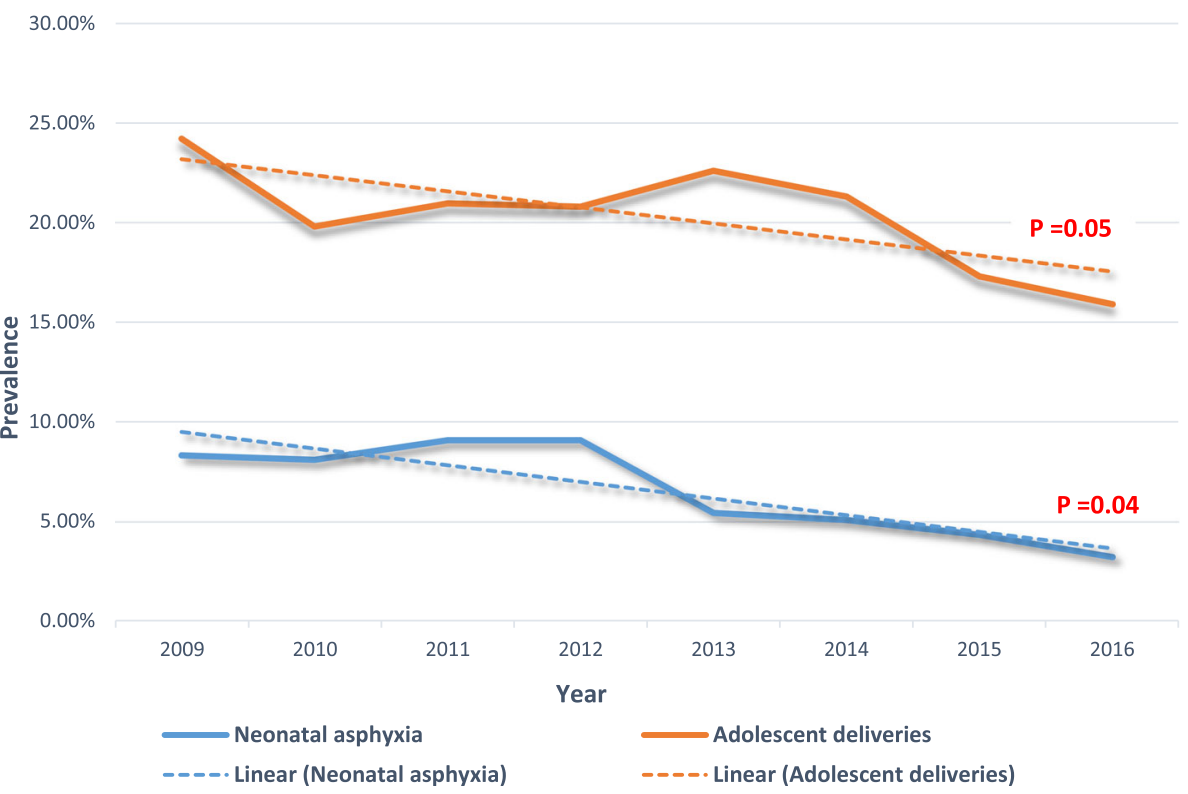

Fig. 1 Trend in the prevalence of adolescent deliveries and neonatal asphyxia at the fifth minute in babies of adolescent mothers from the year 2009 to 2016

In this study, second - fourth degree perineal tears were about three times more likely to complicate adolescent than adult deliveries. Similar findings have been reported across other developing countries [12, 13]. This predisposition has been attributed to a biological immaturity, particularly pelvic and perineal immaturity in adolescents $[5,8,14]$. In addition, nulliparity, a condition which is relatively common in adolescent than adult women, has been shown to increase the risk of potentially severe and devastating fourth degree perineal tears by seven folds $[15,16]$. However, our finding contrasts with those of Fouelifack et al. [8] and Ngowa et al. [9]. During labour, in the study carried out by Fouelifack et al., an episiotomy was immediately done in participants when an increased likelihood of a perineal tear was anticipated in a participant [8]. More so, they found that the odds for an episiotomy to be done was twice greater among adolescents compared with their adult counterparts. This could explain why perineal tears were unlikely to complicate adolescent deliveries in their study. Perineal tears have been attributed to severe and stigmatising complications like obstetric fistulae [17].

The rate of caesarean deliveries in this sub-division was unacceptably low, compared with the recommended 5-15\% caesarean section rate by World Health Organisation (WHO) [18]. This was probably due to the fact that caesarean sections were conducted only at the district hospital where the doctor was stationed, and that caesarean deliveries were only recorded as from the year
2014. Also, factors handicapping a smooth referral system in this district could account for such a low caesarean section rate. Indeed, the mountainous topography of this health district which results in longer referral time, and a relatively high cost of transportation greatly hinders a smooth referral system. Consequently, health facilities distant to the main district hospital, like the Kevu health centre, prefer referring cases requiring emergency caesarean section to nearby districts. Adolescent deliveries were not associated with an increase rate of caesarean deliveries in this study. This finding contrasts with those of many authors $[19,20]$. However, our finding tied with that of Njim et al. [6] and Fouelifack et al. [21].

Adolescent deliveries were significantly associated with LBW and neonatal asphyxia at the fifth minute of life. These findings corroborate with other reports from Africa $[5,6,14,16]$. However, we found no significant association between adolescent pregnancy, stillbirth and preterm delivery reported by other authors $[5,6,22,23]$. Furthermore, it has been stipulated that due to a deficient production of oxytocin secondary to immaturity of the hypothalamoepiphyseal pathway, and uterine immaturity, adolescent pregnancies have a greater tendency to persist beyond term compared with adult pregnancies [21]. Nevertheless, our study, among others $[6,7,10,19]$, showed that adolescent pregnancies are unlikely to exceed the normal term.

Over an 8-year period (2009-2016), there was a remarkable downward trend in the prevalence of adolescent deliveries in this sub-division. Even though, the prevalence of adolescent deliveries remain unacceptably 
high (15.9\% in 2016; Fig. 1). This downward trend in the prevalence corresponds with the decreasing prevalence of adolescent girls who have already commenced their reproductive life in Cameroon, as reported by the World bank and investigators of the Demographic and Health Survey (DHS), 2011 [4, 24]. Over the years, the Ministry of Public Health in Cameroon has developed policies to address sexual reproductive health such as: the National Population Policy in 1992, the "Maternal and Child Health Care and Family Planning Services Policy and Standards" in 1995, and the "Roadmap for Reduction of Maternal and Neonatal Mortality in Cameroon 2006 2015 " [25]. It is noteworthy that none of these policies specifically address adolescent pregnancy and its associated burden [25]. The "Roadmap for Reduction of Maternal and Neonatal Mortality in Cameroon 2006-2015" was supported by the bodies like the WHO, UNICEF and United Nation Development Programme (UNDP), and had as main goal to ameliorate delivery of reproductive health care services, procuring of qualified health personnel, while enhancing capacity building and family planning services for Cameroon's communities [26]. The "Roadmap" has been the main pillar to meet the reproductive and sexual health of the Cameroonian population. To prevent adolescent pregnancies, the "Roadmap" in association with the Department incharge of Health Promotion programmed education of youngsters at community levels on how to prevent adolescent pregnancies. However, the details on how these youngsters were to be educated was not detailed in the "Roadmap". The lack of detailed specific objectives on how to prevent adolescent pregnancy may have attributed to Cameroon not attaining the Millennium Development Goal (MDG) five. Amelioration and effective application of existing government policies to curb the prevalence of adolescent pregnancy and its related burden may go a long way in attaining the Sustainable Development Goal (SDG) three set for the year 2030 [27]. Indeed, the downward trend in the prevalence of adolescent deliveries was associated with a significant, downward trend in the prevalence of neonatal asphyxia at the fifth minute of life of babies born to adolescent mothers. This depicts the impact of public health interventions on the adverse outcome of adolescent deliveries.

\section{Study limitation}

Since this was a retrospective study, we had no influence on the quality of data entered into the delivery registers. Also, this study estimated the prevalence of adolescent deliveries. This might not represent the true prevalence of adolescent deliveries as we did not include abortions and could not estimate if the proportions of adolescents using health facilities were similar to those of adults. However, with the large sample size, the results reflect to a certain degree the situation of adolescent deliveries in rural areas in Bui division.

\section{Conclusion}

Our study reveals a high prevalence of adolescent deliveries in this rural community in Cameroon. Adolescent mothers are more likely to sustain second - fourth degree perineal tears during labour and their babies have a higher tendency of being asphyxiated and/or having LBW. Married adolescents were not precluded from having adverse maternofoetal outcomes when compared with single adolescents. The prevalence of adolescent deliveries has experienced a remarkable downward trend, with a corresponding decreasing trend in the prevalence of neonatal asphyxia at the fifth minute of life in babies born to adolescent mothers, over an 8-year period. Despite this downward trend, the prevalence of adolescent deliveries in this rural community remains high. We recommend not just a reinforcement, but also an effective application of the existing government-based policies to specifically target key indicators of adolescent pregnancy, in order to curb its related complications especially in the rural areas. Also, studies to evaluate qualitative factors such as cultural changes, religious influence and increased service delivery that could explain the observed trend in the prevalence of adolescent deliveries are warranted in this sub-division.

\section{Abbreviations \\ Cl: Confidence interval; HIV: Human immunodeficiency virus; LBW: Low birthweight; NGO: Non-governmental Organisation; OR: Odd's ratio \\ Acknowledgements \\ The authors will like to thank the staff of the Oku district hospital and Kevu primary health centre for their cooperation during the study. \\ Funding \\ None. \\ Availability of data and materials \\ The datasets generated and/or analysed during the current study are available from the corresponding author on reasonable request.}

\section{Authors' contributions}

Study conception and design: VNA and TN; Data collection and analysis: VNA; Write up of first manuscript: VNA; Manuscript revision: VNA, CMM and TN. All authors read and approved the final manuscript.

Ethics approval and consent to participate

Ethical approval was obtained from the scientific and ethical review board of the Northwest Regional delegation for Health.

\section{Consent for publication}

Not applicable.

\section{Competing interests}

The authors declare that they have no competing interests.

\section{Publisher's Note}

Springer Nature remains neutral with regard to jurisdictional claims in published maps and institutional affiliations. 


\section{Author details}

${ }^{1}$ Ibal Sub-divisional Hospital, Oku, Northwest Region, Cameroon. ${ }^{2}$ Mankon Sub-divisional Hospital, Bamenda, Northwest Region, Cameroon. ${ }^{3}$ Centre for Tropical Medicine and Global Health, Nuffield Department of Medicine, University of Oxford, Oxfordshire, UK. ${ }^{4}$ Health and Human Development Research Group (2HD), Douala, Cameroon.

Received: 5 April 2017 Accepted: 11 September 2017

Published online: 29 September 2017

\section{References}

1. WHO. Adolescent pregnancy. WHO. [cited 2016 Nov 27]. Available from: http://www.who.int/mediacentre/factsheets/fs364/en/

2. Vogel JP, Pileggi-Castro C, Chandra-Mouli V, Pileggi VN, Souza JP, Chou D, et al. Millennium Development Goal 5 and adolescents: looking back, moving forward. Arch Dis Child. 2015;100:S43-7.

3. Ezegwui HU, Ikeako LC, Ogbuefi F. Obstetric outcome of teenage pregnancies at a tertiary hospital in Enugu. Nigeria Niger J Clin Pract. 2012; 15:147-50

4. INS/Cameroun IN de la Santé, International ICF. Cameroun Enquête Démographique et de Santé et à Indicateurs Multiples (EDS-MICS) 2011. 2012 [cited 2017 Jan 10]; Available from: http://dhsprogram.com/ publications/publication-fr260-dhs-final-reports.cfm

5. Egbe TO, Omeichu A, Halle-Ekane GE, Tchente CN, Egbe E-N, Oury J-F. Prevalence and outcome of teenage hospital births at the buea health district, South West Region, Cameroon. Reprod Health. 2015;12 [cited 2016 Nov 28] Available from: http://www.ncbi.nlm.nih.gov/pmc/articles/ PMC4690316/

6. Njim T, Choukem S-P, Atashili J, Mbu R. Adolescent Deliveries in a Secondary-Level Care Hospital of Cameroon: A Retrospective Analysis of the Prevalence, 6-Year Trend, and Adverse Outcomes. J Pediatr Adolesc Gynecol. 2016;29:632-4.

7. de Azevedo WF, Diniz MB, da Fonseca ESVB, de Azevedo LMR, Evangelista CB. Complications in adolescent pregnancy: systematic review of the literature. Einstein. 2015:13:618-26.

8. Fouelifack FY, Tameh TY, Mbong EN, Nana PN, Fouedjio JH, Fouogue JT, et al. Outcome of deliveries among adolescent girls at the Yaoundé central hospital. BMC Pregnancy Childbirth. 2014;14:102.

9. Ngowa JDK, Kasia JM, Pisoh WD, Ngassam A, Noa C. Obstetrical and Perinatal Outcomes of Adolescent Pregnancies in Cameroon: A Retrospective Cohort Study at the Yaoundé General Hospital. Open J. Obstet. Gynecol. 2015;5:88

10. Tebeu PM, Kemfang JD, Sandjong DI, Kongnyuy E, Halle G, Doh AS. Geographic Distribution of Childbirth among Adolescents in Cameroon from 2003 to 2005. Obstet Gynecol Int. 2010;2010:e805165.

11. Amoran OE. A comparative analysis of predictors of teenage pregnancy and its prevention in a rural town in Western Nigeria. Int J Equity Health. 2012; $11: 37$

12. Sagili H, Pramya N, Prabhu K, Mascarenhas M, Reddi RP. Are teenage pregnancies at high risk? A comparison study in a developing country. Arch Gynecol Obstet. 2012;285:573-7.

13. Legino LJ, Woods MP, Rayburn WF, McGoogan LS. Third- and fourth-degree perineal tears. 50 year's experience at a university hospital. J Reprod Med. 1988:33:423-6.

14. Kongnyuy EJ, Nana PN, Fomulu N, Wiysonge SC, Kouam L, Doh AS. Adverse perinatal outcomes of adolescent pregnancies in Cameroon. Matern Child Health J. 2008;12:149-54.

15. Landy HJ, Laughon SK, Bailit J, Kominiarek MA, Gonzalez-Quintero VH, Ramirez M, et al. Characteristics Associated With Severe Perineal and Cervical Lacerations During Vaginal Delivery. Obstet Gynecol. 2011:117:627-35.

16. Smith LA, Price N, Simonite V, Burns EE. Incidence of and risk factors for perineal trauma: a prospective observational study. BMC Pregnancy Childbirth. 2013;13:59.

17. Daniilidis A, Markis V, Tzafetas M, Loufopoulos P, Hatzis P, Vrachnis N, et al. Third degree perineal lacerations-How, why and when? A review analysis. Open J Obstet Gynecol. 2012;2:304-10.

18. WHO. Monitoring emergency obstetric care [Internet]. WHO. [cited 2017 Mar 27]. Available from: http://www.who.int/reproductivehealth/ publications/monitoring/9789241547734/en/
19. Yoder BA, Young MK. Neonatal outcomes of teenage pregnancy in a military population. Obstet Gynecol. 1997;90:500-6.

20. Pun KD, Chauhan M. Outcome of adolescent pregnancy at Kathmandu University Hospital, Dhulikhel, Kavre. Kathmandu Univ Med J KUMJ. 2011;9:50-3.

21. Fouelifack FY, Fouedjio JH, Fouogue JT, Fouelifa L, Nguefack D, Mbu RE. Fetal Outcome of Deliveries among Teenagers in Centre Region of Cameroon. Br J Med Med Res. 2015;7:161-8.

22. Kurth F, Bélard S, Mombo-Ngoma G, Schuster K, Adegnika AA, BouyouAkotet MK, et al. Adolescence As Risk Factor for Adverse Pregnancy Outcome in Central Africa - A Cross-Sectional Study. PLoS One. 2010;5 [cited 2016 Nov 28]. Available from: http://www.ncbi.nlm.nih.gov/pmc/ articles/PMC3004789/

23. Althabe F, Moore JL, Gibbons L, Berrueta M, Goudar SS, Chomba E, et al. Adverse maternal and perinatal outcomes in adolescent pregnancies: The Global Network's Maternal Newborn Health Registry study. Reprod Health. 2015;12:S8.

24. The World bank. Adolescent fertility rate (births per 1,000 women ages 1519) | Data. [cited 2017 May 20]. Available from: http://data.worldbank.org/ indicator/SP.ADO.TFRT.

25. Calvès A-E. Assessing Adolescent reproductive health policies and program. Policy working series; 2002 [cited 2017 May 20]. Available from: http:// docplayer.net/41189013-Case-studies-from-burkina-faso-cameroon-and-togo. html.

26. Engen IK. Adolescent Reproductive Health in Cameroon [Internet] [Master Degree in International Social Welfare and Health Policy]. Oslo: Faculty of Social Sciences, Oslo and Akershus University College of Applied Sciences; 2013. [cited 2017 May 20]. Available from: https://oda.hioa.no/en/ adolescent-reproductive-health-in-cameroon-prevention-of-adolescentpregnancies-through-access-to-sexual-and-reproductive-health-measures-incameroon/asset/dspace:5434/Engen_IdaKristin.pdf.

27. Transforming our world: the 2030 Agenda for Sustainable Development. Sustainable Development Knowledge Platform. [cited 2017 Apr 23]. Available from: https://sustainabledevelopment.un.org/post2015/ transformingourworld.

28. Njim T, Atashili J, Mbu R, Choukem S-P. Low birth weight in a sub-urban area of Cameroon: an analysis of the clinical cut-off, incidence, predictors and complications. BMC Pregnancy Childbirth. 2015;15 [cited 2017 Mar 27]. Available from: http://www.ncbi.nlm.nih.gov/pmc/articles/PMC4634914/.

29. Choukem S-P, Njim T, Atashili J, Hamilton-Shield JP, Mbu R. High birth weight in a suburban hospital in Cameroon: an analysis of the clinical cutoff, prevalence, predictors and adverse outcomes. BMJ Open. 2016;6: e011517.

\section{Submit your next manuscript to BioMed Central and we will help you at every step:}

- We accept pre-submission inquiries

- Our selector tool helps you to find the most relevant journal

- We provide round the clock customer support

- Convenient online submission

- Thorough peer review

- Inclusion in PubMed and all major indexing services

- Maximum visibility for your research

Submit your manuscript at www.biomedcentral.com/submit 